\title{
Geomechanical properties of peat stabilized with cement and sand
}

Mehdi Karimi Pashaki, Mohammad Nikookar*, Seyed Mohammad Mirmoa'zen, Mahyar Arabani

Department of Civil Engineering, University of Guilan, Rasht, Iran

\section{ARTICLE IN F O}

\section{Article history:}

Received 28 May 2017

Received in revised form

19 July 2017

Accepted 27 July 2017

\section{Keywords:}

Peat

Stabilize

Geomechanical properties SEM

\begin{abstract}
A B S T R A C T
A large portion of surface layers on earth in moderate regions consist of peat which is the case in northern parts of Iran where peat layers are of considerable depth. Peat has very low strength and is highly compressible under loads and very moisture-sensitive, and thus considered problematic. As a result, stabilizing peat is the aim of many civil engineering projects. In the present experimental study, the effects of cement and sand on geomechanical properties of peat have been studied. The samples were prepared with different cement and sand contents of 5, 10 and $15 \%$ of each additive. To investigate the geomechanical effects of these additives on peat, atterberg limits tests, compaction test, unconfined compressive strength and CBR tests were performed. The results indicated a significant improvement in geotechnical properties of peat which was validated by SEM scanning of samples microstructure.
\end{abstract}

(C) 2017 The Authors. Published by IASE. This is an open access article under the CC BY-NC-ND license (http://creativecommons.org/licenses/by-nc-nd/4.0/).

\section{Introduction}

include thick layers of peat. However, in areas to which it is difficult to transport materials, time and economics affect the project. Therefore, in these regions different methods are used to stabilize soil, rather than soil replacing. Peat is a mixture of organic matters dispersed in wetlands, created under favorable topography and weather conditions through chemical decomposition and consists of plant's fibers and fossilized plants (Edil and Dhowian, 1981). Such soils are quite porous and thus have high moisture contents and are prone to high settlements. Previous research shows that the amount of moisture content in peat soils is around $600 \%$ (Huat, 2004). Peat density is generally lower than other soils, slightly higher than the density of water (1.1-1.2 gr $\left./ \mathrm{cm}^{3}\right)$. Density also depends on the composition of organic matters in the soil. Peat soils are usually very acidic and have a low $\mathrm{pH}$. Moreover, there are four types of organic matter in peat soils, including: humic acid, fulvic acid, Humin and yellow organic acids (Edil, 2003; Huat, 2004). Of these four types of organic matters, humic acid and fulvic acid are established barriers to stabilizing peat, neutralizing stabilizers during chemical reactions and the hydration process. One of the very first scholars who studied the peat and its classification was Von Post (1922). In his classification system, peat is classified under 10 groups of $\mathrm{H} 1$ to $\mathrm{H} 10$, with respect to the decomposition degree. H1 defines non-decomposed soil, with fully discernible plant and fibrous structures and H10 is fully decomposed paste-like soil (Von Post, 1922; Landva and Pheeney, 1980). In recent years, numerous studies have been conducted on peat stabilization. One of the very first 
studies conducted on peat soil stabilization was by Bredenberg et al. (1999). They prepared peat samples from two areas of Sweden and evaluated the effects of adding cement, lime, gypsum and fly ash by consolidation test and unconfined compressive strength test. The results showed that the effect of stabilizers depends on the nature of the peat soil and stress history. The study conducted by Janz and Johansson (2002) showed that lime has little effect on peat stabilization, since peat doesn't contain sufficient minerals which are required for pozzolanic reaction initiated by lime. Therefore, the simultaneous combination of cement and lime will have better results. Furthermore, Hebib and Farrell (2003) showed that the addition of pozzolans such as cement, lime and fly ash could improve the engineering properties of peat. In another study Huat (2004) conducted a series of unconfined compressive strength, density and atterberg limits tests on stabilized peat with 5 to 15 percent of cement and 5 to 25 percent of lime. Their results showed that with increasing cement content, atterberg limits and optimum moisture content decreased and the maximum dry density increased. Also in the comparison between cement and lime, cement has a better performance in stabilizing peat. Kalantari and Huat (2008) study the effect of cement on a number of treated samples in saturated and unsaturated conditions with California bearing ratio (CBR) and unconfined compressive strength (UCS) tests. Their results suggest that CBR values increased with increasing cement and also the values in the saturated condition is less than that in unsaturated condition. The unconfined compressive strength test results showed that with increasing curing period of concrete, the unconfined compressive strength increases, while the strength value decreases by increasing the water-cement ratio (w/c). Wong et al. (2013) observed that as the binder dosage, initial pressure, silica sand and the curing period in water increase, the unconfined compressive strength increases as well along with a decrease in the void spaces based on the results of the scanning electron micrograph of stabilized peat specimens. Kalantari et al. (2012) showed that in the construction of the pavement, a mixture of peat and cement along with fibers can be used as the base course. Fibers in this mixture act in a way that prevents cracks either from formation or further development, leading in an increase in the samples strengths. Moayedi et al. (2013) showed that due to the materials used as the main stabilizer, the UCS results of the stabilized specimens may vary significantly. The results of the study carried out by Dehghanbanadaki et al. (2013) indicated that the mix design of $300 \mathrm{~kg} / \mathrm{m} 3$ cement, with $125 \mathrm{~kg} / \mathrm{m}^{3}$ of well graded sand by wet peat, yielded the highest uniaxial compressive strength at 90 days of curing.

Nikookar et al. (2012) conducted a study on cement-sand stabilized organic-contained soils of Gissom forest area by UCS, CBR and Atterberg limits tests. The results indicated an increase in CBR, UCS and density of treated samples. In a study on lime- stabilized peat by Nikookar et al. (2016), strength parameters of peat were investigated using the UC test and the CU triaxial test along with introducing the equivalent triaxial unconfined strength, i.e. the hypothetical triaxial strength extrapolated in case of zero confining pressure, taking into account the effect of lime content, curing period and the curing conditions, indicating an increase in the value of cohesion along with a decrease in the value of internal friction angle as lime content and curing period increase. Moreover, it was indicated that the unconfined compression strength of peat can be caculated as 0.35 times the aforementioned the equivalent triaxial unconfined strength. Huat (2004) was indicated that cements and lime as binders, along with increasing the strength, neutralize the acidity of peat. Kazemian et al. (2014) indicated that using additives such as cement, sodium silicate and kaolinite decrease the void ratio and the coefficient of secondary compression of treated fibrous peat. Moreover, the effect of three curing techniques of moist curing, air curing and moist curing with surcharge load on the strength of cement-stabilized peat was investigated in a study by Kalantari and Prasad (2014). It was indicated that the moist curing technique yields lower strengths compared to adopting the other two curing techniques.

Md Yusof et al. (2015) investigated the effect of hydrated lime on the compressive strength of peat in a study. An increase in the strength and stiffness was indicated in treated peat.

The purpose of this paper is to summarize the major findings on the effect of cement and sand on atterberg limits, compactibility, and unconfined compressive strength and CBR value of Talesh peat.

\section{Material and methods}

\subsection{Peat}

Peat soil has been identified as one of the major groups of soils comprising the northern area of Iran on the south coast of the Caspian Sea. Peat for this laboratory investigation was obtained at the depth of 0.1 to $0.4 \mathrm{~m}$ below the ground surface from Kolou area in Talesh Mt in Guilan province where there is dense vegetation (Fig. 1).

Since water table was at the ground surface, the soil was completely saturated. From visual observation, the soil color was dark. Based on the characteristics of the peat of this area, this soil is considered H8 in Von Post (1922) classification system. In Table 1 , the basic properties of peat are presented (Nikookar et al., 2014).

\subsection{Cement}

Ordinary Portland cement was used as a binder in this laboratory investigation. Portland cement can be used for with the purpose of modifying and improving the quality of the soil, and transforming the soil into a strong and durable cemented mass 
(Arabani and Karami, 2007). Different cement contents are used to see the effects on soil modification and stabilization. A Portland cement particle is a heterogeneous substance, containing minute tricalcium silicate (C3S) dicalicum (C2S), tricalcium (C3A), and solid solution described as tetra calcium aluminoferrite (C4A). When the pore water of the soil reaches the cement, hydration of the cement occurs rapidly and the major hydration (primary cementitous) produces hydrated calcium silicates (C2SHx, C4AHx), and hydrated lime $\mathrm{Ca}(\mathrm{OH})$ 2 (Bergado, 1996).

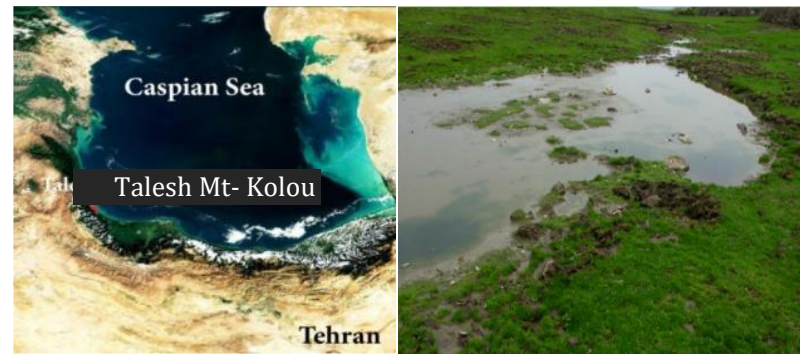

Fig. 1: Kolou area in North of Iran

Table 1: Basic properties of Kolou peat soil

\begin{tabular}{ccc}
\hline Parameters & Standard & Values \\
\hline Depth of Sampling (cm) & - & $10-40$ \\
Maximum Dry Density(g/cm $\left.{ }^{3}\right)$ & ASTM D 698-00 & 1.09 \\
Optimum Moisture Content & ASTM D 698-00 & 29 \\
(\%) & ASTM D 4318-00 & 71.8 \\
Liquid Limit (\%) & ASTM D 4318-00 & 70.9 \\
Plastic Limit (\%) & ASTM D2974- 07a & 85 \\
Organic Content (\%) & ASTM D 854-02 & 1.6 \\
Specific Gravity & ASTM D 2216-98 & 400 \\
Natural Moisture Content (\%) & ASTM D2974-07a & 14.9 \\
Ash Content (\%) & ASTM D 1997-91 & 75 \\
Fiber Content (\%) & ASTM D 4972-01 & 4.2 \\
pH & (Visual) & Dark \\
Color & Von Post (1922) & H8 \\
Degree of Humification & System & \\
\hline
\end{tabular}

\subsection{Sand}

Filling material in this study is a sandy soil from the beaches in Kiashahr Port, Guilan province, Iran. Filler material does not cause any chemical reaction, however, it increases the soil strength more economically, provided that sufficient amount of it is mixed into the soil (Janz and Johansson, 2002). The soil collected was transferred to the Soil Mechanics Laboratory of the University of Guilan and was placed in the oven for 24 hours to dry up. Gradation diagram of the sand of Kiashahr is presented in Fig. 2.

\subsection{Laboratory procedures}

At first, preliminary tests were carried out to determine the basic properties of the soil samples based on ASTM (1999). Next, to remove large and course particles of waste that were mixed with peat, the soil was washed on sieve No.30 $0.733 \mathrm{~mm}$ opening). The mixture of water and peat was poured into the tray and placed in the oven at temperatures no more than $40^{\circ} \mathrm{c}$ to dry up in order to preserve the organic materials of the peat.

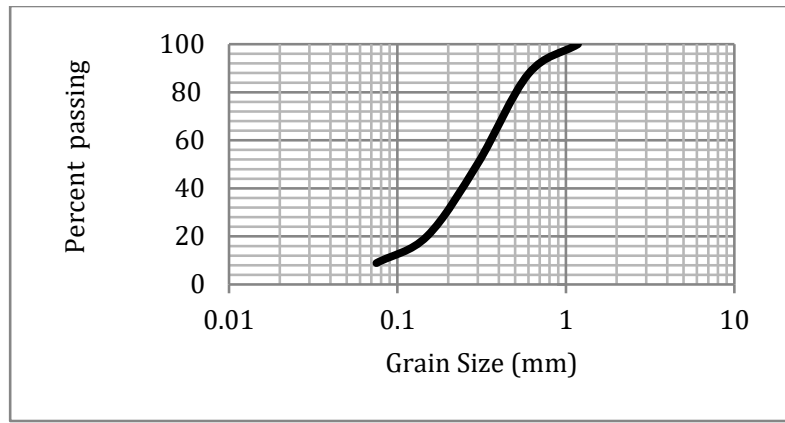

Fig. 2: Gradation diagram of sand of Kiashahr Port

For the unconfined compressive test, the samples were cured for three periods of 7, 14 and 28 days before testing. Samples were prepared at optimum water content and were then removed from the mold inside the desiccator to maintain the moisture. After the curing period, the samples were put in water for 4 hours to be saturated based on ASDM D 1633-96. Then the samples were loaded vertically. Before testing, maximum smoothness of the sample surface must be assured for uniform vertical stress distribution. To do so, the surface was covered with a thin layer of kaolinite. The force and vertical strain values were simultaneously read and recorded at intervals of 30 seconds.

Furthermore, CBR test samples were also prepared in the optimum moisture content and maximum dry density in accordance with ASTM D 1883-99.

\section{Results and discussion}

\subsection{Atterberg limits of stabilized peat}

These tests determine the plastic characteristics of soil in accordance with ASTM D 4318-96. Fig. 3 shows that as the cement and sand is added to the soil, the liquid limit drops. With the addition of $5 \%$ cement to peat, liquid limit has dropped for $15 \%$ and with increasing the amount of cement to 10 and 15 percent, this decrease in the value of liquid limit was more and respectively 23 and $27 \%$. Also it can be observed from Fig. 3 that the minimum liquid limit is for the peat soil sample stabilized with $15 \%$ cement and $15 \%$ sand, showing a reduction of $46 \%$ in comparison to the untreated sample.

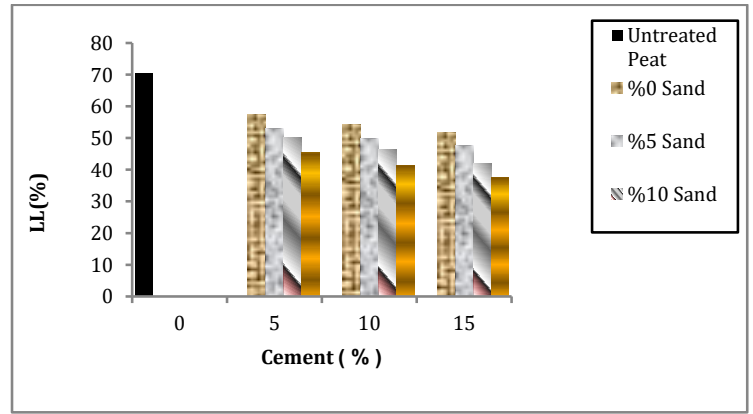

Fig. 3: Liquid limit ratio changes of stabilized peat 
As can be seen from Fig. 4 as the sand and cement contents increase, the plastic limit decreases and the minimum plastic limit is for the sample treated with $15 \%$ of sand and $15 \%$ of cement with the decrease of $44 \%$ in comparison to the untreated sample.

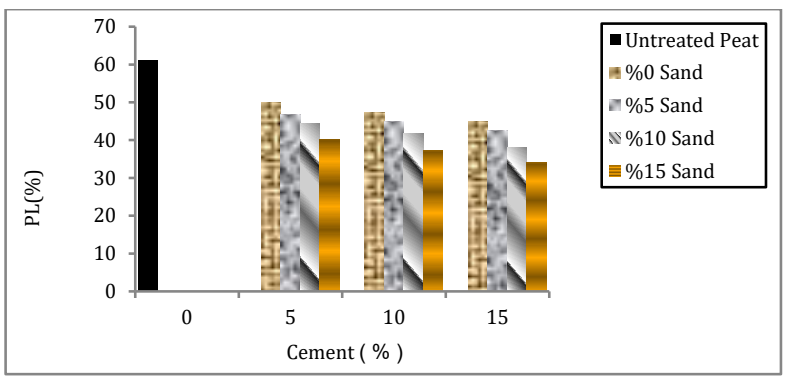

Fig. 4: Plastic limit ratio changes of stabilized peat

Finally the plastic indices values, shown in Fig. 5, are calculated through the values of liquid limits and plastic limits.

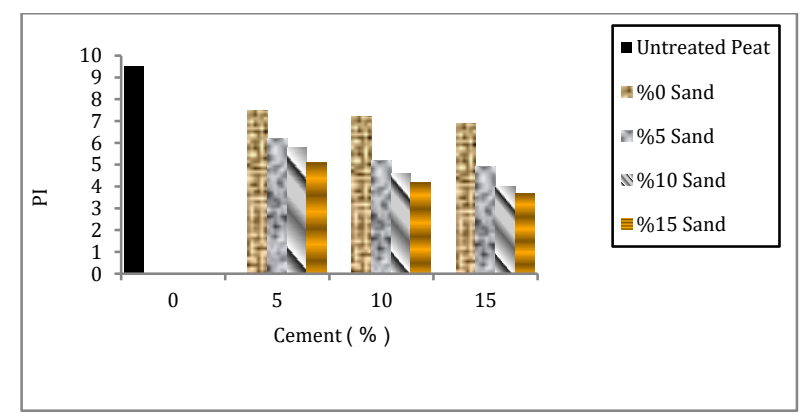

Fig. 5: Plastic index ratio changes of stabilized peat

This decrease in Atterberg Limits can be attributed to hydration process and pozzolanic reaction of cement and moisture which hardens the soil structure. In fact, the difference between plastic limit and Liquid limit depends on specific surface areas and water absorption and inter-particle forces (Deboucha et al., 2008)

\subsection{Compaction characteristics of stabilized peat}

In this study, the standard compression tests were conducted on untreated and treated samples to determine the maximum soil dry density based on ASTM D 698-96 and ASTM D 558-96, respectively. Fig. 5 and Fig. 6 show the effect of cement and sand on the optimum moisture content and maximum dry density of soil stabilized with cement and sand. As seen in Fig. 6, the optimum moisture content decreases as the cement content increases. Moreover, at given cement content, the optimum moisture content decreases with increasing sand content as well. This reduction can be a result of the cementation process of cement. The process itself consumes water and generates heat which leads to further loss of moisture due to evaporation (Nikookar et al., 2012).

As can be seen from Fig. 7, the maximum dry density increases as the cement content increases. Moreover, at given cement content, the optimum moisture content increases with increasing sand content as well. This increase can be attributed the fact that sand and cement particles fill the void spaces in the highly porous peat structure and their densities are considerably higher in comparison to the peat (cement $2506 \mathrm{~kg} / \mathrm{m}^{3}$, sand $1922 \mathrm{~kg} / \mathrm{m}^{3}$, peat $\left.1121 \mathrm{~kg} / \mathrm{m}^{3}\right)$.

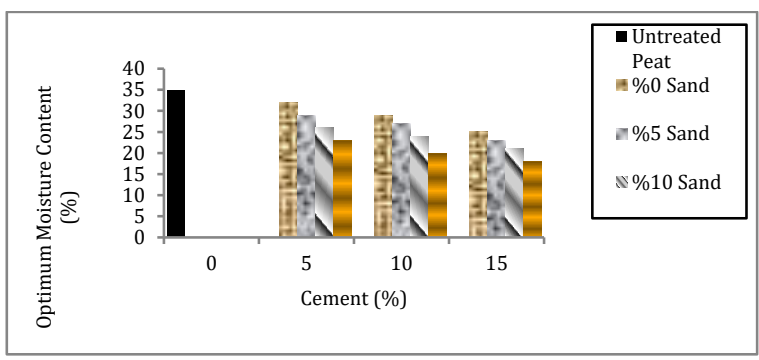

Fig. 6: Effect of cement and sand on optimum moisture content of peat

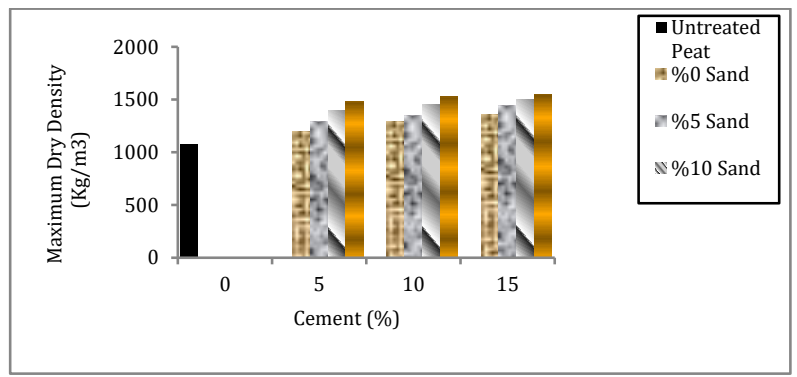

Fig. 7: Effect of cement and sand on maximum dry density of peat

\subsection{Unconfined compressive strength test}

Unconfined compressive strength tests were conducted on untreated and treated samples to determine the maximum soil unconfined strength based on ASTM D 5102-96 and ASTM D 1633-96, respectively. Figs. 8-10 show the values for the maximum compressive strength of the cementstabilized peat. Based on these figures, it is observed that with the addition of $5 \%$ cement, the compressive strength has doubled. Moreover this increase is approximately equal to 3 and five times the original value of the untreated soil for the cement content of 10 and 15 percent, respectively. The results indicate that this increase in the compressive strength is a function of cement content, sand content and the curing period.

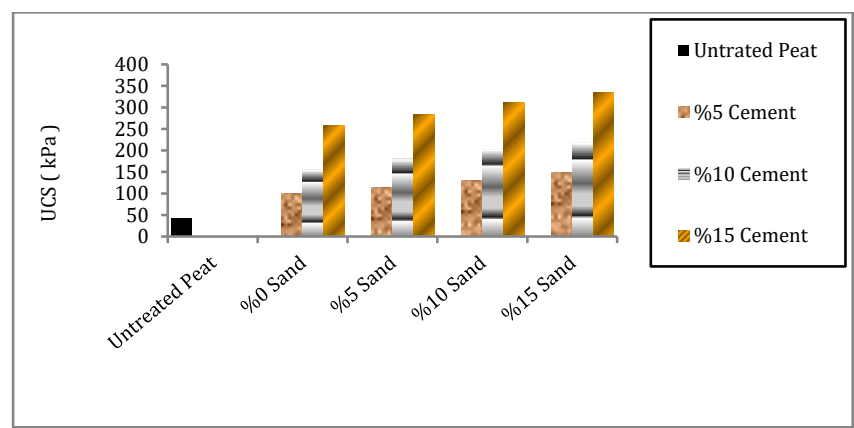

Fig. 8: Changes for increasing the maximum compressive strength of concrete after 7 days curing

This increase in compressive strength can be attributed to the fact that the added cement to the 
soil neutralizes the humic acid which leads to formation of black crystals of calcium silicate hydrates through the cementation process. As a result a uniformly denser structure is created which increases the compressive strength (Deboucha et al., 2008; Wong et al., 2008). Moreover, adding sand to the soil-cement mixture provides more and stronger solid particles for cementation process and improves the soil structure by filling void spaces (Nikookar et al., 2012).

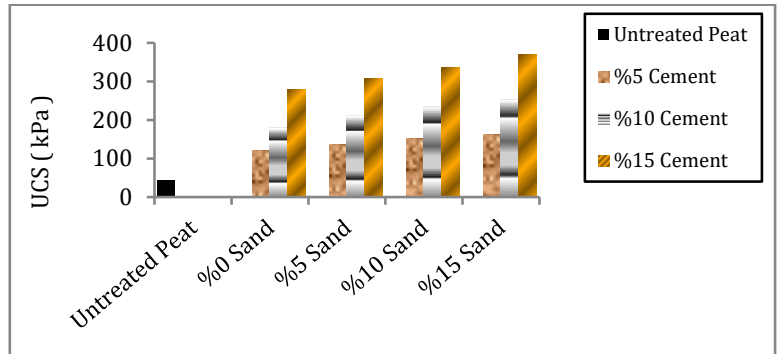

Fig. 9: Changes for increasing the maximum compressive strength of concrete after 14 days curing

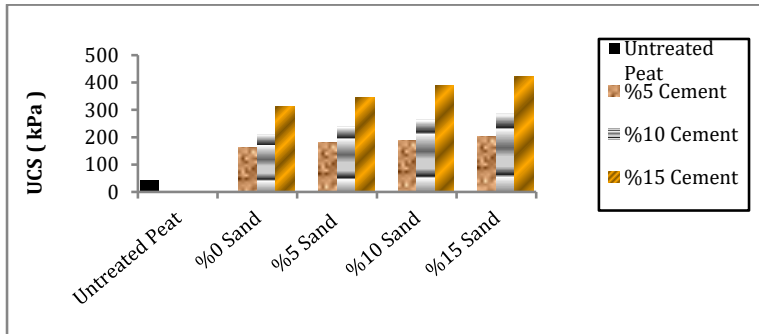

Fig. 10: Changes for increasing the maximum compressive strength of concrete after 28 days curing

\subsection{Tangent modulus of stabilized peat}

The variation of tangent modulus or secant modulus at the maximum $50 \%$ of unconfined compressive strength (E50) for peat stabilized with different percentages of cement and sand are presented in Figs. 11-13. As expected, with higher cement contents and longer curing periods, E50 increases. The variation of E50 values in peat stabilized with cement and sand shows that with cement content of 5\%, E50 value increases up to 2.3 times and with cement contents of $10 \%$ and $15 \%$, the E50 values increase up to 6 and 13 times the initial value, respectively. Moreover, with the addition of $5 \%$ sand to the cement-stabilized soil, the elastic modulus further increased, thus the samples stabilized with $15 \%$ of cement and sand showed the maximum elastic modulus of the study.

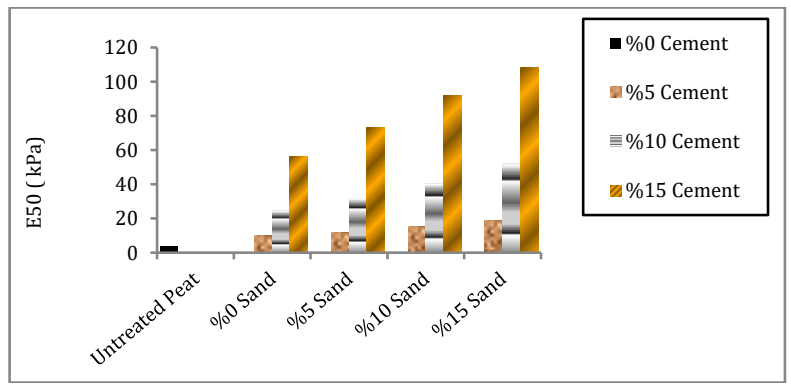

Fig. 11: Tangent modulus of stabilized peat soil after 7 days curing

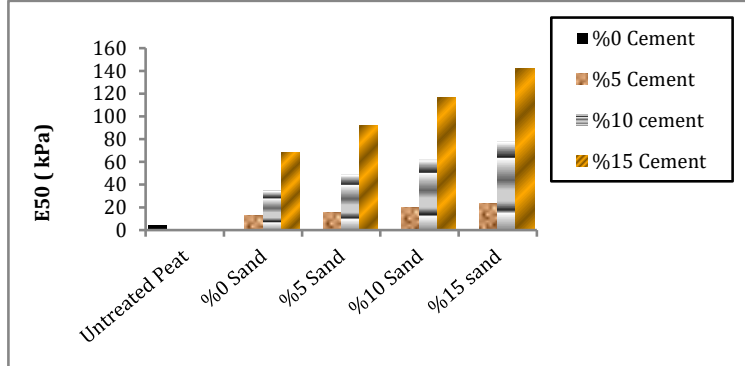

Fig. 12: Tangent modulus of stabilized peat soil after 14 days curing

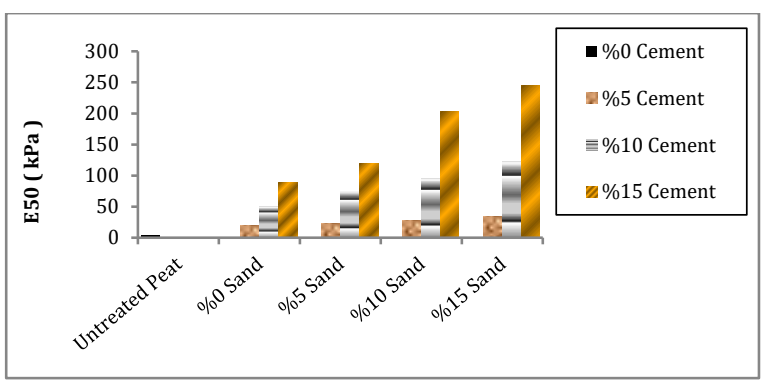

Fig. 13: Tangent modulus of stabilized peat soil after 28 days of curing

\subsection{California Bearing Ratio (CBR) of stabilized peat}

In CBR test, the effect on the strength properties of cement-sand stabilized peat was studied based on ASTM D 1883-99. All specimens were prepared in optimum moisture content and maximum dry density. To compare the results, the CBR values for soil samples containing different contents of cement and sand are shown in Figs 13-15. Results indicate that with the addition of sand and cement to the peat and the subsequent cementation process, the CBR values of stabilized peat with higher additive contents and longer curing period increase significantly.

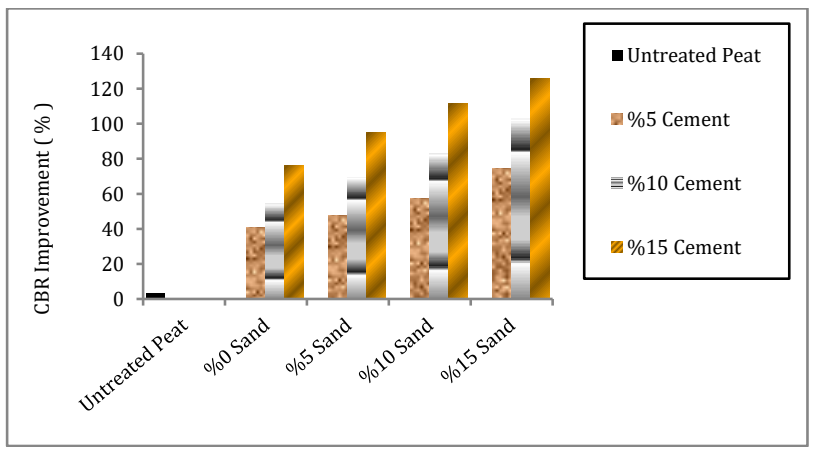

Fig. 14: CBR percent changes of stabilized peat soil samples after 7 days curing

Figures indicate that with the addition of $5 \%$, $10 \%$ and $15 \%$ cement to the peat, the CBR value takes the value of $13 \%, 18 \%$ and $25 \%$ times the untreated CBR value, respectively. Furthermore, adding sand to the cement-stabilized peat leads to higher CBR values. It should be noted that the results are consistent with the results of the unconfined compression test for the stabilized peat samples. 
Such increase in CBR values can be attributed to the fact that the cementation process creates stronger structures and that sand particles fill the voids in the soil structure (Nikookar et al., 2012).

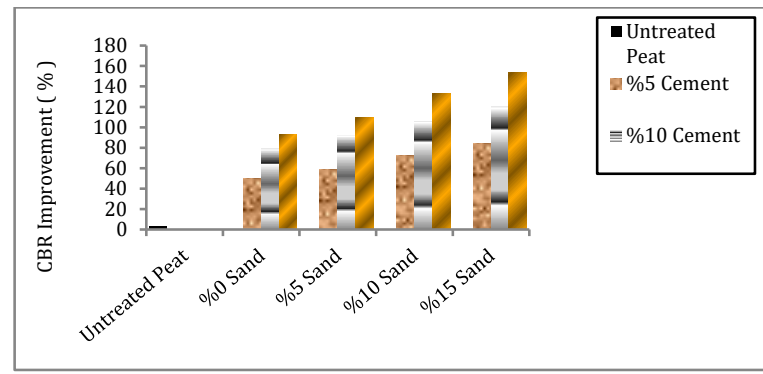

Fig. 15: CBR percent changes of stabilized peat soil samples after 14 days curing

\subsection{Scanning electron micrographs (SEM)}

Using scanning electron microscopy, peat and stabilized peat samples with sand and cement were investigated. Based on the Figs 16-18, it can be seen that the highly porous weak microstructure of peat (Fig. 17) has turned into a much stronger and denser structure as a result of stabilizing with cement along with adding sand since the remaining voids in the stronger microstructure of cement-stabilized peat (Fig. 18) are filled with sand particles (Fig. 19).

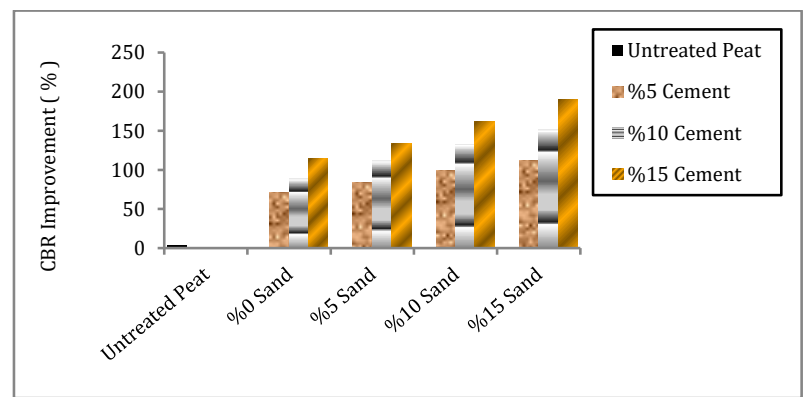

Fig. 16: CBR percent changes of stabilized peat soil samples after 28 days curing

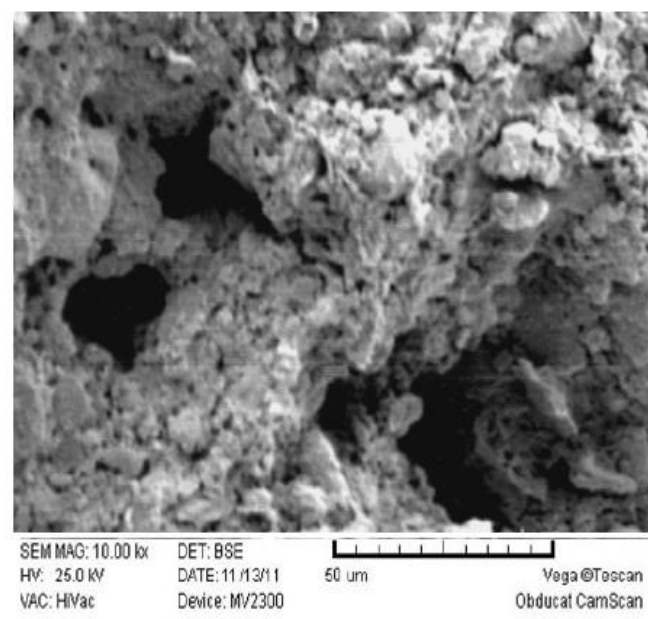

Fig. 17: SEM of untreated peat

As can be seen in Fig. 17, the soil is highly porous which leads to its weak structure, undergoing considerable deformation when subjected to loads. Fig. 18 corresponds to a $15 \%$ cement stabilized peat soil sample with the curing period of 28 days. The cement particles are clearly visible (circular particles) and crystalline calcium silicate hydrate (CSH) particles are scattered among cement and soil particles which reduces the porosity of the soil and creates a denser structure but as can be seen in Fig. 18, despite using $15 \%$ of cement, the structure can become even denser and the porosity can be further reduced. Sand particles can fill the remaining voids and create a much denser structure with minimum porosity which is shown in Fig. 19, corresponding to a sample stabilized with $15 \%$ cement and 15\% sand after 28 days of curing period.

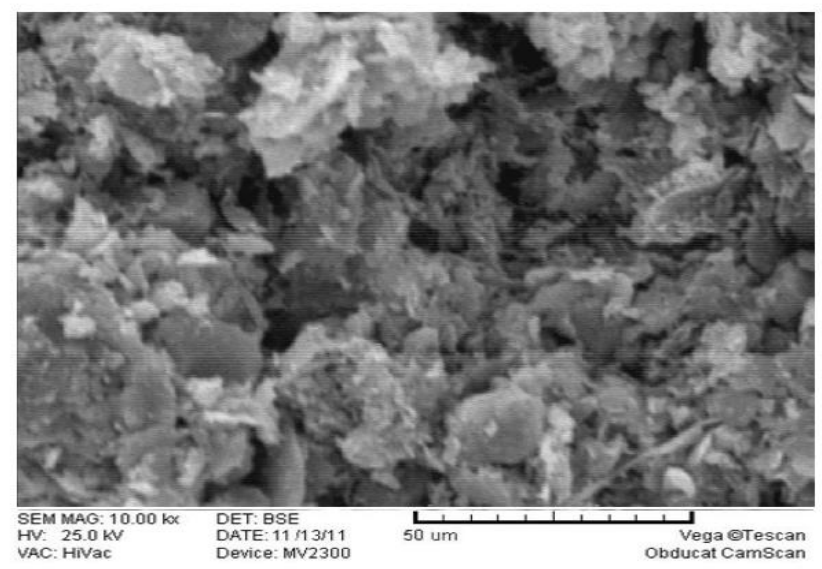

Fig. 18: SEM of peat stabilized with $15 \%$ cement after 28 days curing

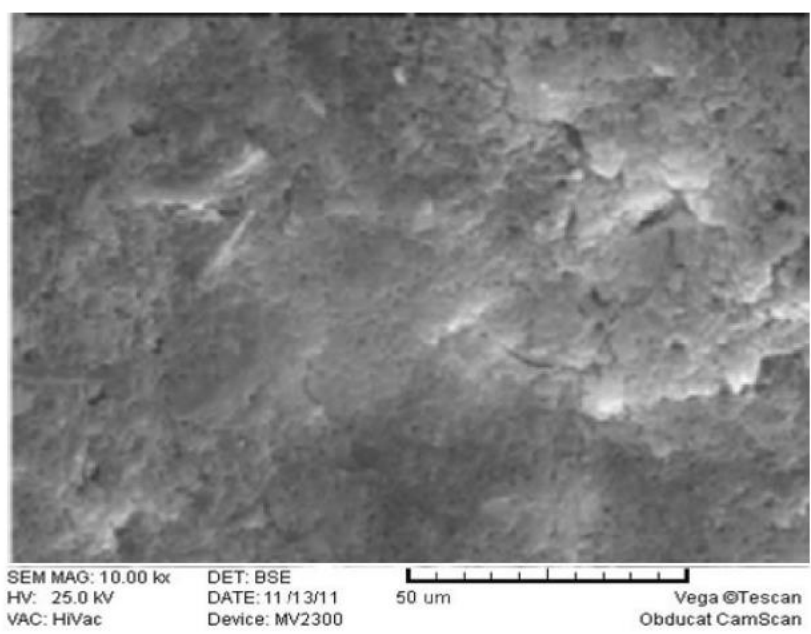

Fig. 19: SEM of peat stabilized with $15 \%$ cement and $15 \%$ sand after 28 days curing

\section{Conclusion}

Based on the Atterberg limit test and compaction test results, the stabilization with cement as binder along with using sand as filler has considerably ameliorated the basic properties of peat. Moreover, USC and CBR test results show a considerable increase in the strength of peat. This increase is correlated to cement and sand contents and the curing period since a longer curing period provides enough time for the cementation process to develop. Such improvement in strength is due to the stronger 
and denser structure resulted from the stabilization which is validated by SEM.

\section{References}

Arabani M and Karami MV (2007). Geomechanical properties of lime stabilized clayey sands. Arabian Journal for Science and Engineering, 32(1B): 11-25.

ASTM (1999). Annual book of ASTM standards, Soil and Rock. American Society for Testing and Materials (ASTM), Philadelphia, USA.

Bergado DT (1996). Soil compaction and soil stabilization by admixtures. In the Conference on Ground Improvement Application to Indonesian Soft Soils, Jakarta, Indonesia: 23-26.

Bredenberg, H, Broms BB, and Holm G (1999). Dry mix methods for deep soil stabilization. CRC Press, Florida, USA.

Deboucha S, Hashim R, and Alwi A (2008). Engineering properties of stabilized tropical peat soils. Electronic Journal of Geotechnical Engineering, 13: 1-9.

Dehghanbanadaki A, Ahmad K, and Ali N (2013). Influence of natural fillers on shear strength of cement treated peat. Građevinar, 65(7): 633-640.

Edil TB (2003). Recent advances in geotechnical characterization and construction over peats and organic soils. In the $2^{\text {nd }}$ International Conference on Advances in Soft Soil Engineering and Technology, Putrajaya, Malaysia: 3-25.

Edil TB and Dhowian AW (1981). At-rest lateral pressure of peat soils. Journal of Geotechnical and Geoenvironmental Engineering, 107(2):201-217.

Hebib S and Farrell ER (2003). Some experiences on the stabilization of Irish peats. Canadian Geotechnical Journal, 40(1): 107-120.

Huat BB (2004).Organic and peat soil engineering. University Putra Malaysia Press, Selangor, Malaysia.

Janz M and Johansson SE (2002). The function of different binding agents in deep stabilization. Swedish Deep Stabilization Research Centre (report 9), Linkoping, Sweden: 1-35.

Kalantari B and Huat BBK (2008). Peat soil Stabilization using ordinary Portland cement, polypropylene fibers, and air curing technique. Electronic Journal of Geotechnical Engineering (Bundle J), 13: 1-13.
Kalantari B and Prasad A (2014). A study of the effect of various curing techniques on the strength of stabilized peat. Transportation Geotechnics, 1(3): 119-128.

Kalantari B, Prasad A, and Huat BB (2012). Use of cement, polypropylene fibers and optimum moisture content values to strengthen peat. International Journal of Physical Sciences, $7(8):$ 1276-1285.

Kazemian S, Moayedi H, and Mosallanezhad M (2014). The effect of cement-sodium silicate grout compounds on void ratio and the coefficient of secondary compression of treated fibrous peat. Journal of Testing and Evaluation, 43(2): 1-7.

Landva AO and Pheeney PE (1980). Peat fabric and structure. Canadian Geotechnical Journal, 17(3): 416-435.

Md Yusof Z, Harris M, Nabillah S, and Mohamed K (2015). Compressive strength improvement of stabilized peat soil by pond ash-hydrated lime admixture. Applied Mechanics and Materials, 747: 242-245.

Moayedi H, Kazemian S, and Huat BB (2013). Shear strength parameters of improved peat by chemical stabilizer. Geotechnical and Geological Engineering, 31(4): 1089-1106.

Nikookar M, Arabani M, Mirmoa'zen S, and Pashaki M (2016). Experimental evaluation of the strength of peat stabilized with hydrated lime. Periodica Polytechnica Civil Engineering, 4(60): 491-502.

Nikookar M, Pashaki MK, and Arabani M (2014). Engineering properties of stabilized soil of gisoom forest area using cement-sand mixture. Advances in Civil and Environmental Engineering, 2(3): 162-171.

Nikookar M, Pashaki MK, Nikookar H, and Arabani M (2012). The geotechnical improvement of Talesh peat soil with cement. In the $3^{\text {rd }}$ International Conference on New Developments in Soil Mechanics and Geotechnical Engineering, Near East University, Nicosia, North Cyprus, 18: 1-16.

Von Post L (1922). Sveriges geologiska undersoknings torvinventering och nagre av dess hittills vunna resultat [Geological peat inventory in Sweden and its results]. Svenska Mosskulturföreningens Tidskrift, 36: 1-27.

Wong LS, Hashim R, and Ali F (2013). Improved strength and reduced permeability of stabilized peat: Focus on application of kaolin as a pozzolanic additive. Construction and Building Materials, 40: 783-792.

Wong LS, Hashim R, and Ali FH (2008). Engineering behaviour of stabilized peat soil. European Journal of Scientific Research, 21(4): 581-591. 